\title{
ASSIMETRIAS DA MEMÓRIA: TRAJETÓRIAS SIMILARES, LEMBRANÇAS DESIGUAIS - MARIA DO CARMO SARMENTO E BETTINA FERRO DE SOUZA, MÉDICAS NO PARÁ
}

Aristóteles Guilliod de Miranda ${ }^{1}$

José Maria de Castro Abreu Júnior ${ }^{2}$

"Não há futuro para a História das mulheres sem um permanente exercício arqueológico da memória"

(Losandro Antônio Tedeschi)

\section{RESUMO}

O artigo aborda as trajetórias de duas médicas paraenses, graduadas pela antiga Faculdade de Medicina e Cirurgia do Pará - atualmente Faculdade de Medicina da Universidade Federal do Pará, na segunda metade da década de 1930, ambas figuras de destaque na especialidade de Cardiologia, que começava a se firmar como tal: Maria do Carmo Sarmento Carvalho, a que primeiro utilizou o aparelho de eletrocardiograma em Belém do Pará, tendo tido, também, grande atividade política pelo Partido Comunista Brasileiro, mas que permanece esquecida em seu pioneirismo; e Bettina Ferro de Souza, que firmou-se como figura destacada tanto na docência quanto na especialidade, tornando-se uma espécie de padroeira da Cardiologia no Pará. As diferenças entre ambas as médicas e os possíveis motivos para que as lembranças relacionadas a elas resultassem tão desiguais, com o apagamento da memória de uma e a celebração da outra, são apresentadas e discutidas, procurando-se explicações para tal fato.

Palavras-chave: História da Medicina. Mulheres na medicina.

\section{MEMORY ASYMMETRIES: SIMILAR PATHS, UNEQUAL MEMORIES - MARIA DO CARMO SARMENTO AND BETTINA FERRO DE SOUZA, DOCTORS IN PARÁ}

\begin{abstract}
This article illustrates the trajectories of two female doctors from state of Pará-Brazil, graduated from the former School of Medicine and Surgery of Pará, now, School of Medicine of Federal University of Pará in the late 1930s, and who had important roles in Cardiology, which had only begun to establish itself as a medicine specialty at the time: Maria do Carmo Sarmento Carvalho and Bettina Ferro de Souza. The former, was the first to use electrocardiography in Belém-Pará, and, who was also a great activist for the Brazilian Communist Party; her pioneering, however, seems to have been forgotten. The latter, stood out both academically, by teaching at the School of Medicine and also, in the Cardiology field, thus becoming some kind of patroness of this specialty in Belem-Pará. The differences between these two women will be presented and discussed in order to try and find the possible reasons why one is celebrated while the other was somewhat erased in the memory of people.
\end{abstract}

Key words: History of Medicine. Women and medicine.

\section{INTRODUÇÃO}

Data de submissão: 03.02 .2021

Data de aprovação:30.04.2021

\footnotetext{
${ }^{1}$ Médico, Doutor em Biologia de Agentes Infecciosos e Parasitários pela Universidade Federal do Pará (UFPA). Médico do Serviço de Cirurgia do Hospital Universitário João de Barros Barreto/UFPA. Sócio Efetivo do Instituto Histórico e Geográfico do Pará. E-mail: guilliod@gmail.com.

${ }^{2}$ Médico, Doutor em História pela UFPA. Professor de Patologia da Faculdade de Medicina da UFPA. Sócio Efetivo do Instituto Histórico e Geográfico do Pará. E-mail: jmcajr@gmail.com.
} 
Estudar comparativamente as sociedades ou a vida de personagens históricos constituise em um método de abordagem dentre tantos utilizados pela História em suas abordagens, sendo clássicos os trabalhos de Plutarco ( 45 d.C - 125 d.C.) contrapondo a vida de figuras de políticos e militares do mundo grego com outras do mundo romano da Antiguidade Clássica. Os 23 pares de biografias comparadas analisados por Plutarco, e que chegaram aos nossos dias, são considerados referência fundamental para a Historiografia, representando um marco nos estudos biográficos, à despeito dos séculos que nos separam da sua elaboração pelo grande polímata grego (JOSÉ, 2009).

Além desse modelo comparativo, as biografias têm ganhado o "recente entusiasmo" dos historiadores, a despeito da complexidade do tema, considerando-se suas ambiguidades. Partindo de uma provocação, para incrementar a discussão - "pode-se escrever a vida de um indivíduo?" Levi (2006, p.167-169), dá a sua resposta: “as biografias individuais só despertam interesse quando ilustram os comportamentos ou as aparências ligadas às condições sociais estatisticamente mais frequentes" (LEVI, 2006, p.174).

Considerando as noções do método comparativo e também a prosopografia, nossa abordagem analisa a trajetória de duas médicas paraenses - Maria do Carmo Sarmento Carvalho e Bettina Ferro de Souza, formadas nos anos de 1930, na Faculdade de Medicina e Cirurgia do Pará, período em que o exercício da medicina por mulheres ainda era incipiente no Brasil ${ }^{3}$. Ambas também se destacaram como pioneiras na mesma especialidade - a cardiologia. Mesmo sendo reconhecidas por seus contemporâneos, uma tem sua memória preservada fazendo parte do inconsciente coletivo notadamente da classe médica de Belém. A outra, raramente é lembrada, aparecendo muitas vezes como "nota" ou "rodapé" nas narrativas memorialísticas tão comuns no ambiente médico. Partindo das suas trajetórias paralelas e suas peculiaridades mulheres, médicas e cardiologistas pioneiras, tenta-se entender onde esses caminhos se distanciam na edificação de suas memórias, ao ponto de uma praticamente desaparecer dos relatos, enquanto que a outra assume aspectos de verdadeira santidade. Em suma, adaptando as palavras de Plutarco nas suas Vidas Paralelas a figuras femininas e atualizando-as por conta das peculiaridades individuais: "Examinarei em confronto o caráter e as disposições de alma de ambas a partir das ações e da vida pública de cada uma, mas renunciarei a comparar seus discursos e a dar opinião sobre qual as duas é mais agradável ou mais hábil ao falar" (VÁRZEAS, 2010, p.35).

\section{MARIA DO CARMO: UM NOME GARIMPADO NOS ESCANINHOS DA MEMÓRIA}

Em 1989, em palestra inaugural à $3^{\text {a }}$ Jornada Paraense de Cardiologia, promovida pela Sociedade Paraense de Cardiologia, o médico Paulo Roberto Pereira Toscano, ao esboçar um histórico dessa especialidade no Pará, fez a seguinte afirmação: "Na década de 40, com a introdução de eletrocardiografia, pela Dra. Maria do Carmo Sarmento, teve início a Cardiologia como especialidade autônoma em Belém" (TOSCANO, 1989, p.24). Além de destacar o papel da médica citada como introdutora da eletrocardiografia em Belém, Toscano descreveu, também, o aparelho que realizava o exame naqueles tempos iniciais:

\footnotetext{
${ }^{3}$ Dados estatísticos da Faculdade de Medicina da UFRJ, antiga Faculdade Nacional de Medicina, uma das principais escolas médicas do país, mostram que, entre 1949 e 1968, o número de médicas formadas correspondia a $10 \%$ do total de egressos por ano. A partir de 1969 começou uma curva crescente que aumentou de 16,48\% para 38,53\% em apenas dois anos. No ano de 1999 o percentual era de 63,51\% (FRANCO, 2001, p.52). Na Faculdade de Medicina da Bahia, a escola médica mais antiga do Brasil, a desproporção entre o número de formados versus formadas também persistiu até a década de 60 do século XX, quando a tendência passou a sofrer progressiva mudança sendo no intervalo de 1980 a 1993 maior o número de médicas formadas do que de médicos (TAVARES-NETO, 2008, p.41).
} 
Dêem asas à imaginação os que estão me ouvindo, para "visualizar" o eletrocardiógrafo de então, tão grande em tamanho como nas dificuldades para operálo, desde a interferência por corrente alternada até o sistema fotográfico de registro do traçado (TOSCANO, 1989, p.24).

Em seguida, acrescentou: "É do meu conhecimento que a pioneira Dra. Maria do Carmo foi uma autodidata, e quanto esforço há de ter despendido para estudar, fazer e interpretar eletrocardiogramas, no início da década de 40" (TOSCANO,1989, p.24).

Na década de 1990, já estava consolidado um grupo de Cardiologia do Hospital da Santa Casa de Misericórdia do Pará o qual ministrava cursos básicos de Eletrocardiograma para estudantes de medicina e para médicos. Na última aula de cada curso, antecedendo o jantar comemorativo, uma personalidade de destaque na Cardiologia era homenageada. Em 1991, a grande homenageada fora a médica Bettina Ferro de Souza, professora de Propedêutica Médica da antiga Faculdade de Medicina e Cirurgia do Pará, atual Faculdade de Medicina da Universidade Federal do Pará, e reconhecida como grande formadora de várias gerações de clínicos e cardiologistas.

Naquela noite, ao saudar a professora Bettina e citando tópicos do vasto currículo da famosa mestra, o médico Tadeu Daibes, pela organização do curso, mencionou ter sido ela "a primeira cardiologista no Pará". Em seu discurso de agradecimento, Bettina, para surpresa de muitos dos presentes, retificou a informação sobre o seu suposto pioneirismo restaurando a verdade ao afirmar que a pioneira fora Maria do Carmo Sarmento, a médica que trouxera o primeiro eletrocardiógrafo para Belém, confirmando a informação anteriormente prestada por Paulo Toscano.

Como resultado da atitude de Bettina, em $1995^{4}$, ao final do curso de Eletrocardiograma, foi a vez da médica Maria do Carmo ser homenageada, tendo sido representada, naquela ocasião, por uma parenta sanando, pelo menos momentaneamente, a falha pelo desconhecimento da sua importância para a medicina no Pará (DAIBES, 2019).

Esses dois fatos, isolados e pontuais, originaram-se de depoimentos, manifestações orais. Para Pollak (1989, p.4) os estudos da História Oral, ressaltam a importância das ditas "memórias subterrâneas", privilegiando a análise dos excluídos, dos marginalizados e das minorias, em uma oposição a dita "memória oficial". Possivelmente o caso da Dra. Maria do Carmo, até aqui à margem da história local, uma outsider por razões que serão brevemente abordadas. O primeiro registro, felizmente reproduzido no jornal, permitiu sua pesquisa na hemeroteca da Biblioteca Nacional, importante ferramenta atual na rede de computadores, nem sempre completa, mas, pelo menos, satisfatória na medida do possível. Se assim não fora, certamente a manifestação do médico Paulo Toscano naquele evento científico teria se perdido para sempre por conta dos caprichos de Mnemosine. ${ }^{5}$

A informação de Tadeu Daibes - a segunda fonte, não pode ser atribuída ao acaso, considerando que o primeiro a ser contatado por nós fora o médico Antônio Castelo Branco, também membro do "grupo dos três" da Cardiologia da Santa Casa, ainda que a propósito de outros assuntos, mas, de qualquer maneira, relacionados à Medicina, como saber sobre um determinado professor da antiga Faculdade de Medicina e Cirurgia do Pará, e complementado pela pergunta: "sabes alguma coisa sobre a Dra. Maria do Carmo Sarmento?". A resposta de

\footnotetext{
${ }^{4}$ O tempo decorrido entre a "descoberta" do feito da médica Maria do Carmo pela professora Bettina e a homenagem àquela pelo grupo da Cardiologia da Santa Casa do Pará deveu-se ao fato de já haver alguns nomes relacionados para ser homenageados, e também à dificuldade em contatar familiares da médica, uma vez que ela não estava morando em Belém, além de o seu estado de saúde não a permitir viajar (DAIBES, 2019).

${ }^{5} \mathrm{Na}$ mitologia grega, a personificação da Memória ou Lembrança. Filha do Céu e da Terra. Júpiter amou-a durante nove noites e, ao fim de nove meses Mnemosine deu à luz as Musas. (Dicionário, 1976, p.124).

${ }^{6}$ Segundo Tadeu Daibes os outros componentes eram os médicos Nelson Gama e Antônio Carlos Castelo Branco.
} 
Antônio Carlos de pouco saber sobre a médica mencionada foi seguida da informação que "talvez o Daibes saiba um pouco mais" (BRANCO, 2019). Memória e esquecimento coexistindo como unidade. Novamente vindo à tona as "memórias subterrâneas" que de maneira quase imperceptível tendem a aflorar em determinados momentos entrando em disputa com as "memórias oficiais" (POLLAK, 1989. p.4).

O contato seguinte, desta vez com o médico Tadeu Daibes, pode parecer à primeira vista que pouco rendera, considerando este somente lembrar-se dos fatos acima narrados e que a homenageada fora representada por uma sobrinha, talvez e que esta era estudante de medicina no Rio de Janeiro. Entretanto, tais referências, aparentemente vagas, sustentam um dos postulados da história oral, qual seja a importância do testemunho oral como núcleo de investigação, jamais como acessório (MIKKA, 1988:132. Apud: AMADO; FERREIRA, 2006, p.xiv).

Sem dispensar um tratamento crítico da fonte oral (VOLDMAN, 2006, p.249), aí é que entra o olhar aguçado do pesquisador, nesse caso, os ouvidos! Na recepção e transformação das duas informações em fato histórico: o reconhecimento do pioneirismo da Dra. Maria do Carmo, evento referendado pela Dra. Bettina, considerada como um ícone da cardiologia paraense e, por tudo isso, legitimada como fonte. Daí em diante "as soluções e explicações devem ser buscadas onde sempre estiveram: na boa e antiga teoria da história" (AMADO; FERREIRA, 2006, p.xvi), desdobrando as informações, cotejando-as, confirmando-as ou não quando possível, refazendo perguntas ou elaborando novas. E foi o que tentamos fazer: preencher lacunas, a partir desses modestos testemunhos buscando a reconstituição do passado.

Os dados fornecidos por Daibes, constituídos pela vivência de fatos posteriormente evocados, podem ser classificados como "arquivos provocados", segundo Jacques Ozouf (Apud BECKER, 2006, p.28), e pertencentes "à mesma categoria das recordações ou memórias" (BECKER, 2006, p.28). Nesse caso específico uma "memória subterrânea" que provocada veio à tona se contrapondo aquela memória coletiva organizada que resume a imagem que uma sociedade majoritária deseja impor (POLLAK, 1989, p.8). Especificamente, neste estudo, a sociedade médica e as memórias que esta deseja reter para si. Considerando que as coletividades, em diferentes tamanhos (partidos, igrejas, famílias, nações) buscam no passado referências para manter coesão dos grupos, definindo seu lugar respectivo, e fornecendo pontos de referência, o que Pollak (1989, p.9) entende como uma "memória enquadrada".

\section{DADOS BIOGRÁFICOS OU QUEM FOI MARIA DO CARMO}

O desconhecimento, inclusive dos cardiologistas paraenses, sobre a médica Maria do Carmo Sarmento foi à tônica do processo de elaboração deste trabalho, sendo poucas as informações obtidas sobre ela, constituindo-se em um viés a mais na abordagem do personagem e permitindo conjecturar os motivos de seu olvido. Sua história oficial dentro da Sociedade Brasileira de Cardiologia se resume a três linhas ressaltando ter iniciado a eletrocardiografia em Belém (LUNA, 1993, p.98). Cabe ao historiador não só acrescentar mais linhas a biografia desta personagem, como também questionar o porquê de a doutora ter ficado à margem da história.

Maria do Carmo Sarmento Ferreira de Carvalho nasceu em Belém, a 5 de maio de 1908, filha de Augusto Paulo de Carvalho, advogado e lente de Francês da Escola Normal, atual Instituto de Educação do Pará (LUCTO, 1916), e Emiliana Sarmento Ferreira, professora catedrática de Francês do antigo Colégio Estadual Paes de Carvalho, e que hoje dá nome a uma escola estadual em Belém (REGO, 2002, p.97 e 99). Por sua filiação depreende-se uma consistente estrutura familiar, com ênfase no aspecto educacional, embora tenha ficado órfã de pai aos seis anos, junto a mais três irmãos (LUCTO, 1916). 
Tendo iniciado seus estudos em 1932, formou-se em 11 de dezembro de 1937 (Figura 1) pela Faculdade de Medicina e Cirurgia do Pará (MIRANDA; ABREU JR., 2009, p.202). Durante sua vida de estudante teve passagem pelo Diretório Acadêmico de Medicina, como membro da Comissão de Beneficência e Previdência (MIRANDA; ABREU JR, 2009, p.215).

Figura entre as 15 primeiras mulheres a graduar-se na mencionada escola médica ${ }^{7}$, fundada em 1919 e que teve seus primeiros formandos em 1924. É considerada pioneira na Cardiologia no Pará, por ter instalado, juntamente com o médico Francisco Rosário Conte, "os primeiros aparelhos de eletrocardiografia em Belém" no Hospital da Santa Casa de Misericórdia (MEIRA, 1986b, p.42).

Figura 1- Maria do Carmo por ocasião de sua colação de grau, em 1937

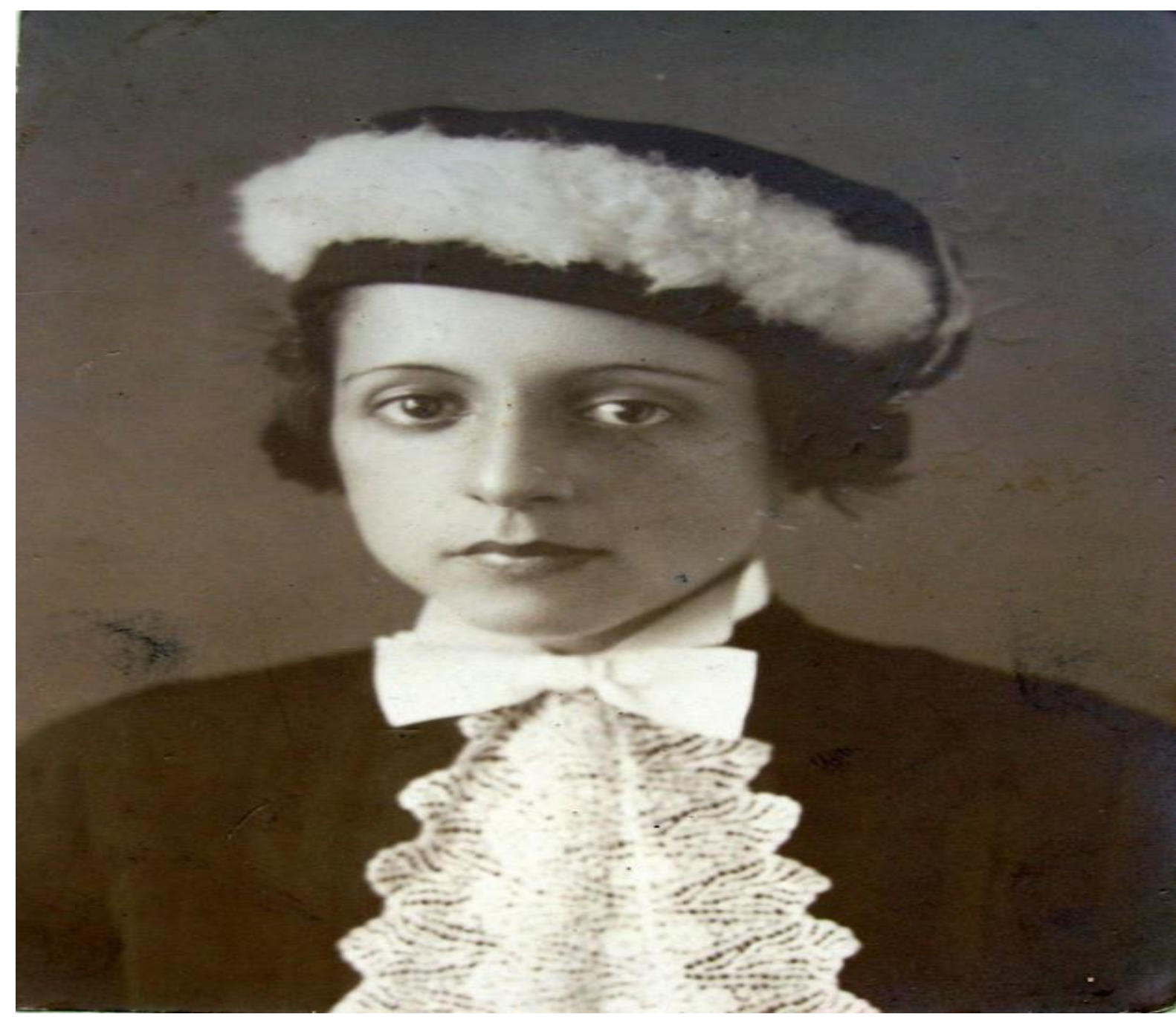

Fonte: Coleção dos autores.

Sua atividade no hospital da Santa Casa proporcionou o convívio com os estudantes de medicina, que utilizavam o hospital para treinamento, tendo inclusive publicado um trabalho científico sobre eletrocardiograma na Revista do Acadêmico de Medicina, órgão do Diretório Acadêmico da faculdade (CARVALHO, 1944), possivelmente um dos primeiros trabalhos realizados em Belém utilizando essa nova ferramenta de trabalho médico ${ }^{8}$.

\footnotetext{
${ }^{7}$ Naquele ano de 1937 formaram-se quatro mulheres (FMCP, 1945, mapa $\mathrm{n}^{\circ} 5$ )

${ }^{8}$ Até agora, no Pará, apenas um trabalho sobre Eletrocardiograma anterior a este é conhecido. Trata-se de um texto de Pedro Borges intitulado "Noções de Electrocardiografia" apresentado na Revista Pará Médico de junho de 1939
} 
Em suas reminiscências dos tempos de estudante de medicina, após definir Maria do Carmo como "colega distinta, estudante, incentivadora dos mais moços" e "cardiologista de reais méritos, introdutora do eletrocardiograma como método propedêutico", Meira assim descreve os primeiros tempos da eletrocardiografia:

Os primeiros aparelhos, muito sensíveis, a eletricidade instável, instalou na Santa Casa um ambiente que neutralizava esses efeitos prejudiciais, uma verdadeira gaiola telada, onde colocava o aparelho e o divã para deitar o paciente (MEIRA, 1990, p.65).

E complementa, lançando luzes sobre a atuação de Maria do Carmo no hospital da Santa Casa naqueles anos iniciais da década de 1940": "Quando estudei clínica médica, com Acylino de Leão, Arthur França e Gastão Vieira, o Rosário Conte, Pedro Borges e Maria do Carmo ensinavam, na qualidade de assistentes" (MEIRA, 1986b, p.42). Ainda, segundo esse autor, ela "funcionava como assistente na Faculdade, mas não chegou a fazer concurso para a cátedra, que veio a ser ocupada por Garcia Filho" (MEIRA, 1990, p.65). Paralelamente, ainda segundo o mesmo autor: "Ensinou muitas gerações de jovens no Ginásio Paes de Carvalho, a cadeira de inglês" (MEIRA, 1990, p.65). Informação não referenciada no livro sobre a história do mencionado colégio, um dado ausente, o qual involuntariamente serve de mais um elemento de reforço de seu esquecimento ou teria Meira a confundido com Emiliana Sarmento Ferreira, professora catedrática de Francês no mencionado colégio e mãe da médica? (REGO, 2002, p.96).

Sua carreira profissional certamente foi impactada pela militância política no Partido Comunista Brasileiro (PCB), tendo pertencido a "uma excelente geração de médicos ligados ao Partido (OLIVEIRA, 2010, p.518). Segundo esse autor: [Maria do Carmo] "médica humanista, sensível aos problemas sociais, interessou-se pelo estudo da filosofia marxista e acabou ingressando no Partido em 1944" integrando a célula Castro Alves (OLIVEIRA, 2010, p.518). Nos arquivos do antigo Departamento de Ordem Política e Social (DOPS), consta uma ficha com o seu nome, datada de 21 de novembro de 1951. O documento não apresenta nem uma anotação além da identificação e de um número de prontuário. Um detalhe: no quadrado onde deveriam ser anotadas características físicas tais como altura, marcas, cabelos, etc., consta destaque, a palavra "Dulce". Seria este um codinome? (DEOPS, 1951).

Na eleição de 2 de dezembro de 1945, à semelhança de outros médicos ligados ao Partido, em nível nacional ${ }^{10}$, candidatou-se a deputada federal, mas não foi eleita (OLIVEIRA, 2010, p.518). Com o cancelamento do registro pelo TSE, em maio de 1947, o PCB entrou novamente na clandestinidade, não obstante Maria do Carmo prosseguiu atuando nas várias ações empreendidas pelo partido. Entre 1949 e 1950, principalmente, fez-se presente em comícios e assembleias, assinou manifestos participando efetivamente da campanha em favor da Paz (OLIVEIRA, 2010, p.518). Em 1952, tornou-se vice-presidente do Movimento pela

(BORGES, 1939, p.10). Diferente do trabalho de Maria do Carmo, fruto de pesquisa com pacientes do Hospital da Santa Casa de Misericórdia do Pará, o trabalho de Pedro Borges, em linhas gerais, é uma revisão teórica do assunto.

${ }^{9}$ Clóvis Olinto de Bastos Meira (1917-2002), paraense, médico formado em 8 de dezembro de 1940 pela então Faculdade de Medicina e Cirurgia do Pará. Professor catedrático de Medicina Legal da Faculdade de Direito da UFPA, destacou-se, também como cirurgião. Foi membro da Academia Paraense de Letras e do Instituto Histórico e Geográfico do Pará. Dentre os vários livros de sua autoria destacam-se: "Médicos de outrora no Pará"; "Medicina de outrora no Pará", "E tempo passou", todos tendo a Medicina paraense e seus personagens como foco central.

${ }^{10}$ Um desses nomes foi Samuel Pessoa, professor de Parasitologia da Faculdade de Medicina da Universidade de São Paulo, que também não conseguiu ser eleito. Por conta de suas posições políticas, Pessoa foi perseguido, desde os anos da Guerra Fria, por sua postura anti-americanista, perseguição exacerbada nos anos da ditadura militar pós-1964.Ver: PAIVA, Carlos Henrique Assunção. Samuel Pessoa: uma trajetória científica no contexto do sanitarismo campanhista e desenvolvimentista no Brasil. Hist. cienc. saúde-Manguinhos, Rio de Janeiro , v. 13, n. 4, p. 795-831, Dec. 2006. 
Vida e Liberdade, o Movil, organizado pelo médico Wilson da Motta Silveira e responsável pela implantação dos Conselhos de Paz, nos bairros de Belém (OLIVEIRA, 2001, p.169).

Em 1955, em apoio a uma campanha pela Amazônia, eterna fornecedora de matériasprima, como borracha, castanha, essências e óleos vegetais, madeiras de lei, mas possuidora de ricas jazidas de minérios, "e, ao que se estima, de um dos maiores lençóis petrolíferos do mundo", e que "está sob controle dos trustes internacionais", juntamente com um grupo de personalidades, Maria do Carmo, assinou o Manifesto de Convocação da Conferência Nacional de Defesa da Amazônia, a ser realizada em Belém entre 13 a 17 de abril de $1955^{11}$ (A AMAZÔNIA, 1955).

Até 1962 participou de uma nova base de médicos do PCB, e embora mantendo suas convicções ideológicas, afastou-se da militância partidária com o golpe militar de 1964 (OLIVEIRA, 2010, 518).

Além da Cardiologia da Santa Casa, aonde chegou à Chefia da Clínica Cardiológica daquele hospital, Maria do Carmo exercia sua atividade profissional na Av. Presidente Vargas, no 145, no edifício Bern, salas 25 e 26 (A Dra. MARIA, 1947; CRM-PA).

Um exemplo do reconhecimento da sua atuação como profissional, acima de tendências políticas, foi o fato de ter sido chamada a Macapá, em 1945, para assistir a esposa do então capitão Janary Gentil Nunes, governador do recém-criado Território Federal do Amapá, vítima de grave cardiopatia (MONTORIL, 2011).

Em consonância com os avanços da Cardiologia, em 1947 comunica "a seus colegas", pelo jornal, a instalação em seu consultório de um "eletro-esteto-esfigmografo Cambridge", colocando-o a disposição em terminados dias da semana (A Dra. MARIA, 1947) ${ }^{12}$. Se considerarmos que a Cardiologia como especialidade estava se organizando, no Brasil, nos anos de 1930, com a chamada "geração pioneira", solidificando-se na década seguinte, tornando-se "plenamente preparado para um progresso até certo ponto rápido" (REIS, 1986, p.376), Maria do Carmo estava perfeitamente sintonizada com os avanços desenvolvidos nos grandes centros do país.

Juntamente com um grupo de 16 médicos, em 16 de maio de 1957, fez parte da fundação da Sociedade Brasileira de Cardiologia - Regional do Pará, mais tarde rebatizada de Sociedade Paraense de Cardiologia (REZENDE, 2002 p.210).

Uma última informação sobre Maria do Carmo vem dos seus apontamentos junto ao Conselho Regional de Medicina do Estado do Pará. Em sua ficha de dados financeiros no referido órgão, consultada em 21 de março de 2003, consta como "aposentada", com dados "atualizados" em 03 de novembro de 1999 (CRM-PA). Se ainda viva naquele ano de 2003, Maria do Carmo estaria com 95 anos, não se sabendo a data da sua morte. A partir desse registro cessam as fontes conhecidas sobre Maria do Carmo Sarmento (como era mais conhecida profissionalmente, com a supressão do sobrenome paterno).

Até onde pudemos apurar, a residência, enquanto viveu em Belém, foi na mesma na avenida Presidente Vargas, no número 351/ 816, no edifício Palácio do Rádio, um dos primeiros prédios modernos construídos naquele perímetro urbano central da cidade de Belém, figurando entre os compradores iniciais do prédio (EDIFÍCIO, 1952).

\section{INTERMEZZO: O ELETROCARDIÓGRAFO}

\footnotetext{
${ }^{11}$ Em pesquisa nos jornais de Belém, do período referido, não encontramos nenhuma notícia dando conta da realização da mencionada conferência. (N.A.)

${ }^{12}$ Supomos tratar-se de um modelo inicial, mais rudimentar àquele que seria mais tarde conhecido simplesmente como eletrocardiógrafo. (N.A.)
} 
A história da invenção/criação do eletrocardiógrafo foge ao propósito desse artigo. Entretanto, torna-se necessário contextualizar o início da sua efetiva utilização na prática médica para entendermos o que isso significa, historicamente, para a medicina no Pará ${ }^{13}$.

Segundo Reis (1986, p.373), os [dois] primeiros eletrocardiógrafos - "tipo galvanômetro de corda" chegaram ao Brasil por volta de 1910-1912, sendo instalados no antigo Hospício da Praia Vermelha, atual prédio da Universidade Federal do Rio de Janeiro e no Hospital da Santa Casa do Rio de Janeiro, respectivamente.

Nos anos de 1920, em razão de várias modificações, os aparelhos diminuíram de tamanho e peso, podendo ser transportados com mais facilidade, e, como tal, permitindo a ampliação de seu uso em vários ambientes. O primeiro aparelho verdadeiramente portátil foi fabricado em Londres em 1929. Ainda assim, pesava em torno de $13 \mathrm{~kg}$ (BURCH; De PASQUALE 1990, p.41), fato confirmado pelo resumo de artigo, publicado na revista Brazil Médico, de 1930, onde se lê:

Um novo electro-cardiographo facilmente transportavel - $\mathrm{CH}$. J. KELLER (Leipzig, da Clinica do prof. Morawitz) - Munchener mediziniszhe Wochenschrift n.30, pag. 1267, 1930 .

O autor recommenda o novo apparelho que é fornecido pela Phys. Und med. Apparatebau-Geselschaft, Freiburg, in B., Zahringestr., preço 1:500\$000. Vantagens: Suporta muito bem o transporte e pesa, apenas, 12 kilos. O modo de usar o apparelho não exige grande aprendizagem; qualquer enfermeira póde com duas ou tres lições manejal-o. O apparelho é muito sensivel de sorte que as curvas podem ser lidas sem correcção. O gasto de corrente é minimo. O novo apparelho vem contribuir enormentemente para a diffusão da electrocardiographia na clinica domiciliar. M.R.J (BRAZIL MÉDICO, 1930, p.10).

E continua Reis (1986, p.376) relatando sobre o surto de progresso e evolução da cardiologia brasileira, na segunda metade da década de 1930 e início da de 1940, inclusive com a criação de uma Sociedade da especialidade, sendo considerado pelo autor como "os anos heroicos da cardiologia nacional". Para esse autor, após a geração" pioneira, "nos anos 40, o meio cardiológico brasileiro já estava plenamente preparado para um progresso até certo ponto rápido" (REIS, 1986, p.376).

É nesse contexto que se inicia em Belém o uso do eletrocardiógrafo, pela Dra. Maria do Carmo Sarmento de Carvalho, logo seguida por outros médicos interessados na revolucionária novidade tecnológica no campo da medicina, dentre estes Bettina Ferro de Souza, e da qual certamente já tinham conhecimento, considerando que até os meados da década de 1930, a formação médica até então era voltada para a Europa, predominantemente de origem francesa e alemã (SOUZA, 2017, p.37) de onde chegavam os livros e as novidades.

Um fato restou sem resposta nesse relato: como o primeiro eletrocardiógrafo chegou a Belém nos anos de 1930? E por que foi parar nas mãos de Maria do Carmo? Os autores que escreveram sobre ambas as médicas nada falam a respeito. De acordo com o médico Jorge Alberto Langbeck Ohana, a médica lhe revelara que o aparelho fora trazido, a seu pedido, por um comandante de navio que fazia linha da Europa até Belém e com quem manteve algum relacionamento. Ainda, segundo Ohana, Maria do Carmo chegou a viajar no navio pelo baixo Amazonas até Manaus, realizando atendimento médico aos habitantes dos locais de parada da embarcação (OHANA, 2019). Perdido o nome do protagonista e a sua nacionalidade, poderíamos falar nos "traçados do coração" corroborando essa história? Quem sabe.

\section{A “CANDURA EM PESSOA" OU ERA UMA VEZ A BETTINA}

\footnotetext{
${ }^{13}$ Entre as inúmeras obras, citaríamos o trabalho de Burch e DePasquale - A history of electrocardiography, - por nós aqui utilizado. (N.A.)
} 
Ao revisarmos os textos produzidos sobre História da Medicina ao longo dos últimos 50 anos, no estado do Pará, observa-se a tradição de memorialistas, médicos em sua maioria, destacando-se a figura de Clóvis Meira, com narrativas heroicas dos grandes fatos ou personalidades consideradas importantes. É esse memorialista quem descreve uma "festa promovida pelo Centro de Ciências da Saúde, no auditório da antiga Faculdade de Medicina e Cirurgia do Pará", para homenagear professores da mencionada faculdade, "que se aposentavam, depois de longo tirocínio no ensino". Além de José Monteiro Leite, catedrático de Anatomia Patológica, e Heber Chilon Monção, assistente de Pediatria, figurava, também, Bettina Ferro e Souza, professora titular de Propedêutica Médica, e, segundo o autor, "todos notáveis educadores", descritos também como "bons médicos, excelentes professores, conduta ética irrepreensível e preparo intelectual do mais alto nível” (MEIRA, 1986a, p.227).

As palavras de Meira particularmente sobre Bettina "a candura em pessoa", conferem a ela um certo sopro de divindade, que se tornaria habitual nas narrativas sobre essa médica, tratamento fartamente empregado por Alencar (2013, p.23) em seu trabalho com o intuito de "resgatar a trajetória profissional e de vida da professora Bettina", [...] "em virtude da contribuição da referida docente para a história da medicina no Pará e no país", em uma postura assumidamente ufanista.

Segundo Meira: “A Bettina, formada com a turma de 1935, a mais antiga, era dos anos 30, uma das primeiras mulheres a se formar em medicina, antecedida por Olga Paes de Andrade e Lucidéa Lobato" ${ }^{14}$.

Bettina Ferro de Souza, paraense de Belém, nascida em uma família de 9 irmãos (ALENCAR, 2013, p.25), em 14 de maio de 1913, era filha de João Batista Ferreira de Souza e de Zuleide Ferro de Souza. Seu pai era advogado e professor de Latim e de Direito, além de político pelo Partido Civilista, pelo qual chegou a senador. Sua mãe, professora, faleceu quando a futura médica tinha 8 anos de idade, passando a responsabilidade de sua criação e dos outros irmãos para a irmã mais velha, Maria Amélia, na ocasião com 14 anos. Formada em medicina pela Faculdade de Medicina e Cirurgia do Pará, em 08 de dezembro de 1935 (Figura 2) (REZENDE, 2001, p.48), "próximo de 1950 [...], após fazer um curso no Rio de Janeiro, começou a exercer a Cardiologia Clínica, já com 'status' de especialidade", segundo (TOSCANO, 1989, p.24). Em 3 de outubro de 1949 assumiu o cargo de médica do Instituto de Aposentadoria e Pensões dos Comerciários (IAPC), por concurso público (REZENDE, 2001. p.49). A docência iniciou-se em 1950, "na condição de instrutora de ensino não remunerada, da $2^{\text {a }}$ Cadeira de Clínica Médica da Faculdade de Medicina e Cirurgia da UFPA, vinculando-se, posteriormente à disciplina de Propedêutica Médica, em 1952, "e dela fazendo um apostolado, até a sua aposentadoria" (TOSCANO, 1993, p.85), tornando-se Livre Docente de Clínica Propedêutica Médica em 1953, defendendo a tese "Beribéri e Cardiopatia" (TOSCANO, 1993, p.86). Para esse autor:

A abordagem científica mais antiga da Cardiologia, que se tem notícia, em Belém, ocorreu em 1956, através de dois cursos proferidos pela prof. ${ }^{a}$ Bettina: "Alguns aspectos da Cardiologia Clínica" (para alunos da $5^{\mathrm{a}}$ e $6^{\mathrm{a}}$ séries do curso médico) e "Noções de Eletrocardiografia", em 18 aulas, durante 2 meses.

Para Meira:

[Bettina] Sempre foi muito estudiosa, aplicadíssima, aluna exemplar. Trazia essa aura do Ginásio Paes de Carvalho. Quando o professor perguntava alguma coisa a alguém

\footnotetext{
${ }^{14}$ Cronologicamente, Bettina Ferro de Souza foi a $9^{\text {a }}$ mulher a se formar pela então FMCP (Ver: MIRANDA;
} ABREU JR., 2009). 
e ninguém sabia, podia perguntar à Bettina. Vinha sempre a resposta, recordam seus contemporâneos" (MEIRA, 1986a, p.227).

Professora por vocação sabia ensinar e prender a atenção dos alunos, ainda que professando uma cadeira difícil de ser transmitida (...) [Bettina] é de uma acuidade excepcional no uso dos sentidos. Tem um ouvido de ouro, dizem todos. Suas possibilidades de diagnosticar podem ser tidas como de certeza, sempre confirmadas pelos aparelhos eletrônicos sofisticados. Dedicada à Clínica e ao Ensino, tem vivido para os pacientes e os alunos, sempre somando e fazendo crescer a aura de simpatia e de cultura que orna seu espírito" (MEIRA, 1986a, p.228).

Figura 2 - Bettina Ferro por ocasião de sua colação de grau, em 1935

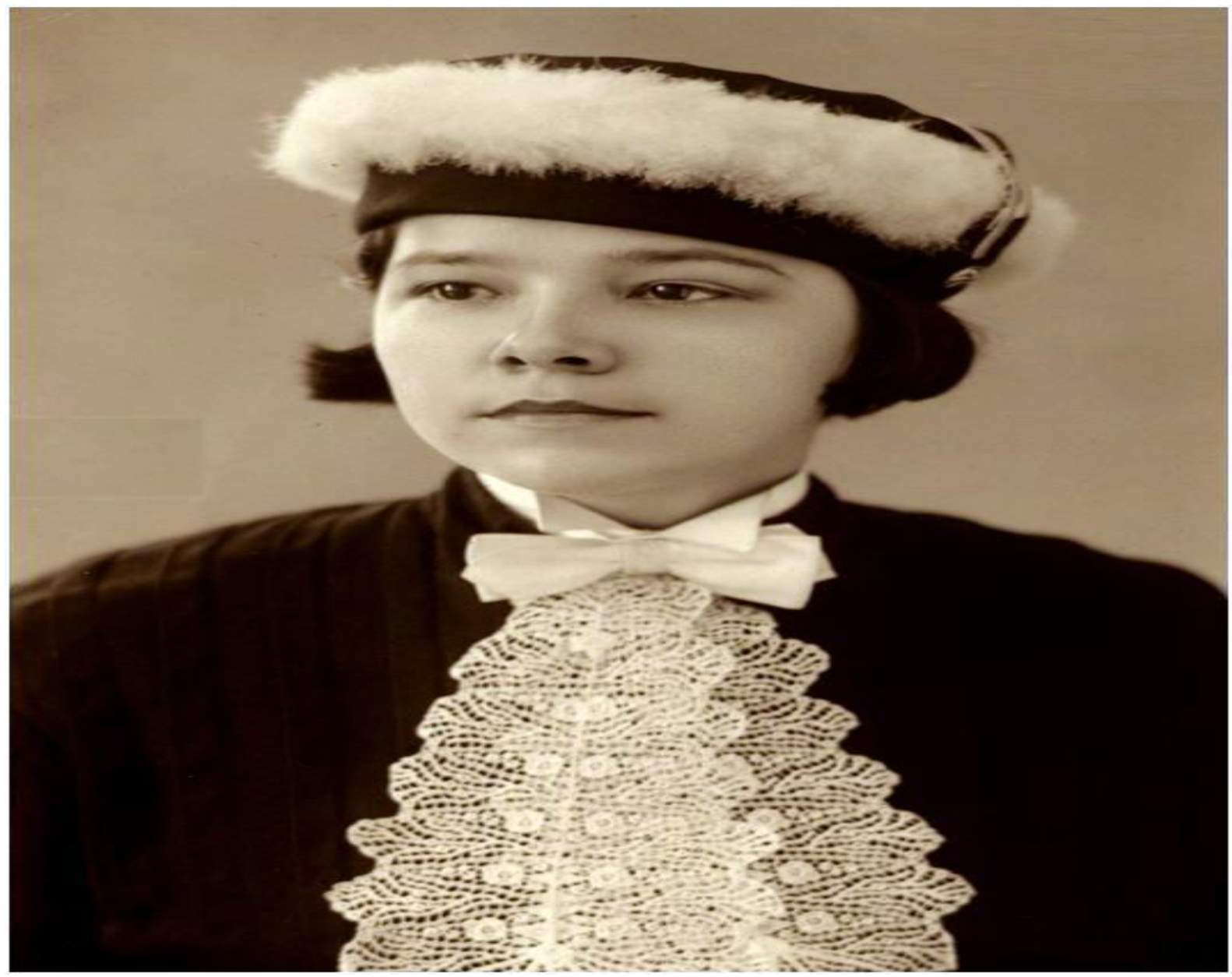

Fonte: Coleção dos autores.

Bettina foi a fundadora e primeira presidente, em 1957, da Sociedade Brasileira de Cardiologia - Secção do Pará, hoje Sociedade Paraense de Cardiologia. Em 1970, organizou o Congresso Brasileiro de Cardiologia, realizado em Belém do Pará, tornando-se a primeira mulher a presidir a entidade nacional (REZENDE, 2001, p.49). Em 1974 torna-se professora Titular da disciplina de Clínica Propedêutica Médica, sendo aposentada pela compulsória em 1983 (ALENCAR, 2013, p.125 e 127).

Paralelamente ao aspecto profissional, científico, Bettina teve também uma faceta pessoal marcante - suas atividades religiosas: foi catequista, na igreja de São João Batista, na Cidade Velha, organizadora de pastorinhas, "em louvação ao Menino Jesus e as apresentava em teatrinhos religiosos de Belém (REZENDE, 2001, p.49). 
Bettina tem o seu lado "humano" representado pela fala de um dos seus vários ex-alunos e discípulos. O médico Murilo de Souza Morhy é quem nos conta que quando a Faculdade de Medicina precisou abrir outra turma de Propedêutica Médica, disciplina em que ela era a única mulher professora, ela conseguiu reunir em torno dela somente professores mais jovens, assumindo uma posição de liderança, sem atritos. E com o detalhe de, geralmente após as reuniões deliberativas com seus assistentes, sempre rolava um uisquezinho, apreciado prazerosamente pela mestra (MORHY, 2019). Ela era Ferro de Souza, mas não era de ferro!

\section{5 À GUISA DE CONCLUSÃO OU CAMARADA DO CARMO VERSUS BEATA BETTINA}

Seria possível atribuir o silêncio sobre o papel da médica Maria do Carmo Sarmento no desenvolvimento da Cardiologia paraense à figura da professora Bettina? Pensar num apagamento de memória feminina ironicamente por outra mulher? Acreditamos que não; que embora a memória da médica Bettina tenha permanecido, ela própria contribuiu para a manutenção da memória da Maria do Carmo, ao reconhecer o papel desta nos primórdios da cardiologia no Pará.

Se ambas podem ser consideradas precursoras em vários sentidos "a primeira cardiologista", "a primeira professora", "a primeira Titular", não podemos deixar de levar em conta a época em que se formaram e iniciaram as suas atividades profissionais: as décadas de 1930-40, período em que as mudanças sociais se fizeram sentir, por meio de políticas sociais e educacionais, possibilitando novas oportunidades profissionais para as mulheres, sobretudo às pertencentes aos extratos superiores de uma sociedade que se urbanizava e se modernizava, à mulher sendo atribuídos novos papeis (AZEVEDO; FERREIRA, 2006, p.241). Neste processo, a educação exercendo um papel, ainda que a presença da mulher, particularmente na medicina, fosse exceção. As palavras de Rezende (2001, p.49) sobre Bettina, guardadas as proporções, fazem sentido, também para Maria do Carmo:

\footnotetext{
A Professora Bettina venceu, resolutamente, as dificuldades e os preconceito da época, pela concretização daquilo que, para muitos, se resumia em simples aspiração. Ela soube imprimir, às vitórias, um cunho de sua personalidade forte e perseverante. No Brasil, na primeira metade do século XX, a organização universitária privilegiava as profissões tradicionais de médico, professor, engenheiro e advogado. As duas primeiras foram, por ela, escolhidas por vocação e por tradição. [...]. Por sua competência de dedicação construiu clientela heterogênea sob o ponto de vista social, com predomínio dos pobres e dos mais desamparados, extensão de sua convicção religiosa.
}

Se existem pontos em comum, como o fato de ambas terem iniciado sua profissão praticamente ao mesmo tempo, no final dos anos de 1930 e início dos anos de 1940, quando novas tecnologias começavam a ser utilizadas na medicina - neste caso, o eletrocardiograma, grandes são as diferenças entre elas.

Bettina fez o modelo tradicional do que se esperava de uma mulher: comportada e obediente; estudiosa e competente; religiosa e cumpridora de tarefas; o perfil idealizado para o modelo de médico enquadrado no que pede/pedia a sociedade, ainda que, de certo modo, por sua competência tenha sido uma precursora ao ponto de conseguir ocupar lugares tradicionalmente reservados aos homens, como a docência no ensino superior e até cargos de direção no ambiente acadêmico. Isso tudo lhe conferiu um quê de santidade nos arraiais da medicina paraense, gerando seguidores e verdadeiros devotos, à semelhança do que aconteceu com a memória de Camilo Salgado.

É possível fazer um paralelo com o proposto por Goffman (2001, p.17) quando o autor estuda o que denomina "instituições totais" (manicômios, prisões e conventos), cujos 
mecanismos acarretam consequências na formação do indivíduo que delas participam sob determinada condição. Por extensão, podemos entender a medicina, como uma "profíssão totalizante"; um médico o será 24 horas por dia, mesmo depois de sua aposentadoria, e a sociedade médica e não-médica vai exigir dele um modo de agir, uma postura, uma espécie de "enquadramento" mediado pela imposição de regras de conduta, uma espécie de conversão a determinados valores.

Bettina preenche essas expectativas do que se esperava de uma mulher que exercesse a medicina naquele período: dedicação total ao ofício, cujas únicas atividades paralelas seriam às ligadas à igreja e que serviriam como elemento de reforço à visão caritativa que a profissão médica reivindica para si. A professora dedicada e desapegada que, conforme nos conta Alencar (2013, p.62), foi capaz de doar até seu anel de formatura para a igreja, sendo dessa autora a contribuição mais recente para a fixação da memória de Bettina nos moldes citados, na obra intitulada "A trajetória de Bettina Ferro e sua contribuição para a ciência e a sociedade" (ALENCAR, 2013). Obra mais de admiradora, a autora se vê, de alguma forma, refletida na biografada, gerando uma forte identificação, expressando-se na personalidade daquele que escreve, o que, por vezes, tende a omitir aspectos da vida do biografado que de algum modo sejam menos relevantes para a autora. O estudo é, portanto, calcado na tradição de uma história moral e estruturada em personalidades modelares nas suas virtudes, predestinadas à pátria e/ou a serviço de Deus (LEVILLAIN, 2003, p.149), destacando-se uma valorização da personalidade que acaba por heroicizar a protagonista.

Maria do Carmo, por outro lado, assumiu uma postura divergente, por seu posicionamento e ativismo político, em um momento em que o campo político era ainda mais restrito para mulheres do que a medicina, além da orientação partidária de Maria do Carmo, ao optar pelo Partido Comunista Brasileiro, instituição que viveu boa parte da sua existência na clandestinidade, sempre estigmatizado, mesmo em dias de "promessas democráticas", e cujos membros, não raro, acabavam em algum momento presos (OLIVEIRA, 2009). Questão que deve ter lhe acarretado problemas até mesmo em suas relações pessoais, a despeito da sua competência e pioneirismo - aqui, particularmente, comprovado pela inovadora utilização do eletrocardiograma como ferramenta na prática médica, com o reconhecimento inclusive daquela que se tornaria ícone na cardiologia do Pará, como exemplo, podemos citar o médico Jorge Alberto Langbeck Ohana, que conversou com a Dra. Maria do Carmo em 1999, ocasião na qual a mesma, mesmo apresentando lapsos de memória, recordou não ter conseguido se tornar professora na Faculdade de Medicina, pois os dirigentes da instituição não gostavam de sua pessoa (OHANA, 2019), afirmação que pode ser interpretada como consequência da sua militância política, considerando o engajamento ideológico da direção da faculdade. Foram grandes, portanto, os obstáculos para o seu merecido reconhecimento como profissional, contribuindo para o silêncio em torno da sua real contribuição para o desenvolvimento da ciência médica no estado do Pará.

Maria do Carmo é o exemplo do que Sarlo (2007, p.17) define como sujeito marginal, ignorado pelos modos de narrar o passado; no caso específico, a história tradicional, institucional e oficial. Daí a necessidade de garimpar vestígios de sua existência na tradição oral já que esta personagem escapa aos cânones de memória.

\section{AGRADECIMENTOS}

Agradecemos aos médicos Tadeu Daibes, Antônio Carlos Castelo Branco, Murilo Morhy e Jorge Ohana pelos depoimentos sobre as médicas Maria do Carmo e Bettina. Ao professor Dr. Aldrin Moura de Figueiredo pela leitura e sugestões dos originais, e à professora Dra. Maíra Maia pelas indicações de leituras para a fundamentação teórica deste trabalho. 


\section{REFERÊNCIAS}

ALENCAR, Cristina. A trajetória de Bettina Ferro e sua contribuição para a ciência e a sociedade. Belém: Ponto Press Ltda, 2013.

A AMAZÔNIA está ameaçada e é preciso defendê-la. Imprensa Popular, Rio de Janeiro, p.6 6 mar. 1955.

A DRA. MARIA do Carmo Sarmento de Carvalho. A Província do Pará, p.3. 9 fev 1947. AMADO, Janaína; FERREIRA, Marieta de Moraes. Apresentação. In: Usos e abusos da história oral. Organização Janaína Amado e Maria Julieta de Moraes Ferreira. $8^{\mathrm{a}}$ ed. Rio de Janeiro/ Editora FGV, 2006.

AZEVEDO, Nara; FERREIRA, Luiz Otávio. Modernização, políticas públicas e sistema de gênero no Brasil: educação e profissionalização feminina entre as décadas de 1920-1940.

Cadernos Pagu, Campinas, n.27, p.213-254. jul.-dez. 2006. Disponível em https://www.scielo.br/pdf/cpa/n27/32143.pdf. Acesso em: 26 maio 2019.

BECKER, Jean-Jacques. O handcap do a posteriori. In: Usos e abusos da história oral. Organização Janaína Amado e Marieta de Moraes Ferreira. $8^{a}$ ed. Rio de Janeiro/ Editora FGV, 2006.

BORGES, Pedro. Noções de Electrocardiografia. Revista Pará Médico, Belém, Ano XXI, N.48, p.11, jun 1939.

BRANCO, Antonio Carlos Castelo. Informação pessoal. 2019.

BURCH, George Edward; DePASQUALE, Nicholas. A history of electrocardiography. California: Norman Publishing, 1990.

CRM-PA. Conselho Regional de Medicina do Estado do Pará. Documentos pessoais de Maria do Carmo Sarmento de Carvalho.

CARVALHO, Maria Sarmento de. Considerações acerca do trifasismo de QRS. Revista do Academico de Medicina. Belém, Ano 2, n.3, p. 15-18, fev 1944.

DAIBES. Tadeu. Informação pessoal. 2019.

DICIONARIO DE MITOLOGIA GRECO-ROMANA. 2 ed. São Paulo: Editora Abril, 1976 DINIZ, Carlos Alberto Nogueira. Fragmentos da memória; $O$ historiador e os arquivos pessoais. p195-207. Disponível em:

http://www.uel.br/eventos/sepech/sepech12/arqtxt/PDF/carlosandiniz.pdf. Acesso em: 27 maio 2019.

DEOPS. Ficha de Maria do Carmo Sarmento Carvalho, 1951. Arquivo Público de São Paulo. EDIFÍCIO Palácio do Rádio. A Província do Pará, 25 dez 1952, p.3.

FACULDADE de Medicina e Cirurgia do Pará. Relatório do ano de 1944. Belém, Oficinas Gráficas da Revista de Veterinária, 1945. 
FRANCO, Talita Romero. Médicas Pioneiras. In: A Faculdade de Medicina Primaz do Rio de Janeiro em Dois dos Cinco Séculos de História do Brasil. Organização Marleide da Mota Gomes; Sylvia da Silveira Mello Vargas; Almir Fraga Valladares. Rio de Janeiro: Atheneu, 2001.

GOFFMAN, Erving. Manicômios, Prisões e Conventos. 7 ed. São Paulo: Editora Perspectiva, 2001.

JOSÉ, Natália Frazão. Plutarco de Queronéia e suas Vidas Paralelas. ISSN 1807-1783, 2009. Disponível em: http://www.historiaehistoria.com.br Acesso em: 24 nov. 2020.

LEVILLAIN, Philippe. Os protagonistas: da biografia. In: Por uma história política. Organização René Rémond. 2.ed. Rio de Janeiro: FGV, 2003. p.141-84.

LEVI, Giovanni. Usos da biografia. In: Usos e abusos da história oral. Organização Janaina Amado e Marieta de Moraes Ferreira. 8. ed. Rio de Janeiro: Editora FGV, 2006.

LUCTO. Estado do Pará, p.2, 7 abril 1916.

LUNA, Rafael Leite. Sociedade Brasileira de Cardiologia. Cinquenta anos de História. Belo Horizonte: BG Cultural, 1993.

MEIRA, Clovis Olinto de Bastos. Médicos de outrora no Pará. Belém: Grafisa, 1986 ${ }^{\text {a }}$

MEIRA, Clovis Olinto de Bastos. Medicina de outrora no Pará. Belém: Grafisa, 1986b.

MEIRA, Clovis Olinto de Bastos. Vultos e memórias do eterno. Belém: Grafisa, 1989.

MEIRA, Clovis Olinto de Bastos. E o tempo passou. Belém: Grafisa, 1990.

MIRANDA, Aristoteles Guilliod de; ABREU Jr., José Maria de Castro. Memória histórica da Faculdade de Medicina e Cirurgia do Pará. 1919-1950. Da fundação à federalização. Belém, ed.autor. 2009.

MONTORIL Nilson. O desenlace de Iracema Carvão Nunes. Disponível em: http://montorilaraujo.blogspot.com/2011/07/o-desenlace-de-iracema-carvao-nunes.html. Acesso em: 23 maio 2019.

MORHY, Murilo de Souza. Informação pessoal, 2019

OHANA, Jorge Alberto Langbeck. Informação pessoal, 2019.

OLIVEIRA, Alfredo. Cabanos e Camaradas. Belém, ed. Autor, 2009.

OLIVEIRA, Alfredo. Resumo histórico do PCB no Pará.in: Política democrática - Revista de Política e Cultura, Brasilia/DF: Fundação Astrojildo Pereira, 2001. № 30, jul 2001, 200 p.

PAIVA, Carlos Henrique Assunção. Samuel Pessoa: uma trajetória científica no contexto do sanitarismo campanhista e desenvolvimentista no Brasil. Hist. cienc. saude-Manguinhos, Rio de Janeiro, v.13, n.4, p. 795-831, Dec. 2006. Available from. Disponível em : 
http://www.scielo.br/scielo.php?script=sci_arttext\&pid=S010459702006000400002\&lng=en \&nrm=iso. Acesso em : 16 jan. 2021.

POLLAK, Michael. Memória, Esquecimento, Silêncio. Estudos Históricos. Rio de Janeiro, vol. 2, n.3, 1989, p.3-15.

REGO, Clóvis Silva de Moraes. Subsídios para a história do Colégio Estadual Paes de Carvalho. Belém: EDUFPA/L\&A Editora, 2002.

REIS, Nelson Botelho. Evolução histórica da Cardiologia no Brasil. Arquivos Brasileiros de Cardiologia. 46/6 371-376. Junho, 1986. Disponível em:

http://publicacoes.cardiol.br/portal/portal-publicacoes//Pdfs/ABC/1986/v46n6/46060002.pdf. Acesso em: 29 maio 2019.

REZENDE, Manoel Barbosa de. Bettina Ferro de Souza: 1913-1993. Revista Pará-Médico. Belém, v.8, n.1, p.49-49, set.-out. 2001.

REZENDE, Manoel Barbosa de. A Sociedade Brasileira de Cardiologia Regional do Pará. In: BORDALO, Alípio Augusto; BICHARA, Carlos David Araújo; PANDOLFO, Sérgio Martins (org.). A Sociedade Médico-Cirúrgica e a medicina no Pará. Belém: ed., 2002, p.209-213.

SARLO, Beatriz. Tempo presente: cultura da memória e guinada subjetiva. São Paulo: Companhia das Letras; Belo Horizonte: UFMG, 2007.

SOUZA, Rodrigo Otávio Paim. História da cardiologia no Brasil: a construção de uma especialidade médica (1937-1958) - Rio de Janeiro. Dissertação (Mestrado em História das Ciências e da Saúde) - Fundação Oswaldo Cruz. Casa de Oswaldo Cruz, 2017, 158 f.

TAVARES-NETO, José (org.); OLIVEIRA, Vilma Lima Nonato de; SANTIAGO, Eliane da Cruz; SANTOS; Francisca da Cunha (cols.). Formados de 1812 a 2008 pela Faculdade de Medicina da Bahia. Feira de Santana: Academia de Medicina de Feira de Santana, 2008.

TOSCANO, Paulo. A cardiologia no Pará: visão do passado e antevisão do futuro. O Liberal, Belém, p.24, 18 jun 1989.

TOSCANO, Paulo Roberto Pereira. Bettina, a cardiologista - perfil biográfico. An. Acad. Med. Pará v.4 p.85-87, 1993.

UM NOVO electro-cadiographo facilmente transportavel. Brazil Medico, Rio de Janeiro, anno XLIV, n.38, p.10, 20 setembro de1930.

VÁRZEAS, Marta. Introdução. in PLUTARCO: Vidas Paralelas. Demóstenes e Cícero. Trad. Marta Várzeas. $1^{\mathrm{a}}$ ed.Lisboa: Centro de Estudos Clássicos e Humanisticos:

Universidade de Coimbra/Faculdade de Letras. 2010.

VOLDMAN, Daniele. A invenção do depoimento oral. In: FERREIRA, Maria Julieta de Moraes; AMADO, Janaína (coord.). Usos e abusos da história oral. $8^{\text {a }}$ ed. Rio de Janeiro: Editora FGV, 2006. 